Journal of Engineering and Applied Sciences 14 (5): 1585-1589, 2019

ISSN: 1816-949X

(C) Medwell Journals, 2019

\title{
Analysis of the Colombian Logistics Performance Index Compared to other Latin American Countries
}

\author{
Pablo Garzon Carreno and Holman Montiel Ariza \\ Universidad Distrital Francisco Jose de Caldas, Bogota, Colombia
}

\begin{abstract}
The objective of this research is to perform an analysis of the current Colombian Logistic Performance Index, evaluating the short-term recommendations provided by the Colombia 2017 Competitiveness Report prepared by ANALTEX. This analysis takes into account a series of vital factors associated with the respective performance index such as: infrastructure, transport and logistics; Seeking to identify the main challenges and action plans that allow the improvement of the logistic processes of the country compared to Latin America and the world.
\end{abstract}

Key words: Logistics Performance Index, competitiveness, production, competitiveness indicators, analysis, recommendations

\section{INTRODUCTION}

For the business organizations in general, the implementation and use of indicators allows an evaluation of the management developed in their daily activities, leading to the search of challenges that potentiate the performance of their work in order to combat the market demands to be more competitive at national and regional levels (Padmavathi and Thangadurai, 2016). At a business and productive level, one of the greatest challenges that Colombia is facing is the improvement in logistics processes in all its areas from the reception of raw materials to the delivery of final products by land, sea or air distribution.

Regarding the results obtained in the logistic performance index of the world bank with the collaboration of National Association of Foreign Trade (ANALTEX for its Spanish initials) (Nandini et al., 2016) it was evident that from 2007-2016 Colombia improved its position in the Latin America Region from being in the 15th position went up to the number 12th (18 countries in the region). On the other hand, 160 nations are those that compose this indicator, Colombia obtains a low logistic performance compared to the total percentage of the evaluated countries, clearly identifying that the country is far below in terms of logistics performance worldwide; In addition to deficiencies in the quality of the infrastructure, Colombia's low logistic performance is due to other critical factors such as problems of efficiency and effectiveness in customs, difficulties in contracting shipments at competitive prices, lack of tracking and placement of the shipments and the scarce competition and quality of the logistics services.

In order to improve the future qualification of the country in the logistic performance it is necessary to analyze the current state with the rest of the Latin American and world area as reference, betting on a series of recommendations supported on the National Competitiveness Report 2016-2017, seeking to carry out an adequate interpretation of the variable behavior of the country in the last evaluations carried out, supporting in this way the tendency to rise or fall in the ranking associated with the logistic performance index.

\section{MATERIALS AND METHODS}

First, a brief description of what the logistic performance index is and what factors are taken into account at the time of evaluation will be given. On the other hand, the behavior of the classification of the indices will be analyzed through a traceability for Colombia which runs from 2007-2016. And finally, a comparative analysis of Colombia will be carried out with Panama, since, this country it is the best placed of the region according to the ranking of the logistic performance index.

The type of analysis is based on the main recommendations that were delivered in the National Competitiveness Report (Bonin-Font et al., 2008) which in its contents deepens the logistic performance,

Corresponding Author: Pablo Garzon Carreno, Universidad Distrital Francisco Jose de Caldas, Bogota, Colombia 
emphasizing infrastructure, transport and logistics. This study by means of a comparative description will show a list of suggestions that has a specific term in this case only research with the short-term factors, illustrating the type of process that can be done for the fulfillment of these. On the other hand it will be evident who can make the difference in the execution of said suggestions and finally, the type of recommendation which emphasizes the department in charge of planning and executing them (Wu and Sun, 2013; Brosnan and Sun, 2004; Kumar and Verma, 2010).

\section{RESULTS AND DISCUSSION}

According to ANALTEX, "The Logistic Performance Index is intended to measure the performance of the supply chain of a country, also, this index allows countries to identify opportunities and challenges to improve in each of the factors taken into account in this comparative index." This index takes into account the following factors: (Padmavathi and Thangadurai, 2016).

Customs: Refers to the efficiency of the clearance process (speed, simplicity and predictability of procedures) by the border control agencies.

Infrastructure: Referring to the quality of infrastructure related to trade and transport (for example, ports, railways, roads, information technology).

International shipments: That is the ease of processing shipments at competitive prices.

Quality and competence in logistics: (Competition and quality of logistics services, for example, transport operators, customs agents, etc.)

Tracking: That is the ability to track shipments.

Punctuality: Meaning that it is the deadline for submitting the shipments within the scheduled or planned delivery period.

Behavior of Colombia in the LPI score, since, 2007: Figure 1 shows the performance of the Colombian Logistics Performance Index score from 2007-2016. It can be clearly seen that Colombia does not have a relevant growth index in the last 10 years because to the lack of implementation of policies associated with the search for innovation and improvement of competitiveness in this sector (Nandini et al., 2016).

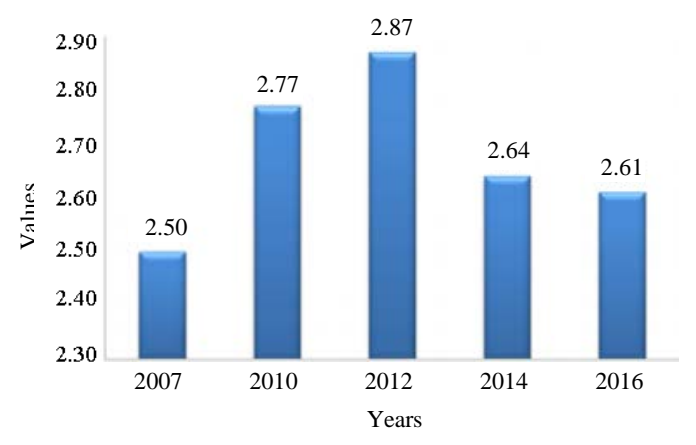

Fig. 1: Colombia-LPI score

Table 1 shows the difference in classification comparing to Panama, since, this is the best placed country in Latin America, showing in this way a good reference regarding the current state of the country in this issue (Nandini et al., 2016).

Figure 2 illustrates the general score of each of the countries that conforms the Latin American Region, clearly shows that Colombia is poorly positioned respect to the region's logistics performance, located in the tenth place and surpassing only to nations such as Bolivia and Venezuela, leaving a lot to think about the management carried out so far.

\section{Analysis of recommendations}

Ensure the financing of the fourth generation of concessions (4G): The main purposes of this project are the improvement of the entire road network and infrastructure throughout the national territory and the reduction of costs for the execution of these projects. For this, it is necessary to keep in mind that before the research execution an analysis and topographical study must be done that indicates the index of lands movement for the different spaces where it is wanted to carry out said implementation in order to obtain a higher reliability in the development of the research.

On the other hand, financing is the most important pillar to achieve the objective that has been stipulated from the beginning. That is why, it should be analyzed what percentage of capital should be contributed by public and private entities that will be directly favored with the implementation of these aspirations and what percentage corresponds to the nation; This is achieved with the resources usage visualization for each of the parties. It must be kept in mind that international aid may be taken into account as these will also benefit in the future (Foreign investors) (Padmavathi and Thangadurai, 2016; Amaya et al., 2017; Bonin-Font et al., 2008). 


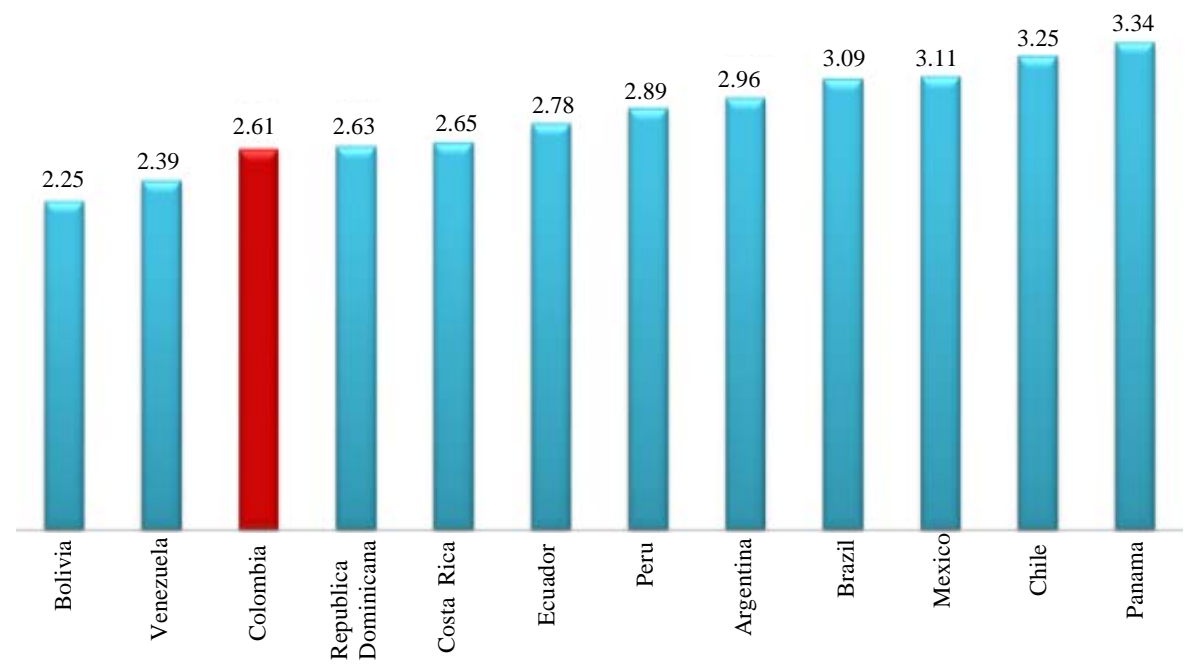

Fig. 2: Latin America-LPI score in 2016

Table 1: Comparative table Colombia vs. Panama

\begin{tabular}{lccc}
\hline Item & Colombia & Panama & Difference \\
Customs & 2.21 & 3.13 & 0.92 \\
Infrastructure & 2.43 & 3.28 & 0.85 \\
International deliveries & 2.55 & 3.65 & 1.1 \\
Quality and logistics competence & 2.67 & 3.18 & 0.51 \\
Tracking and tracking & 2.55 & 2.95 & 0.4 \\
Punctuality & 3.23 & 3.74 & 0.51 \\
\hline
\end{tabular}

Regarding biddings it is necessary to be more rigorous, since, these are the ones that will give the green light to the execution of the research. Therefore, it is prudent for the delivery of these work plans to carry out continuous monitoring to be more precise in the execution and delivery of them and thus the reliability of the service provision has more guarantees to be able for best results.

Establish a clear, expeditious and balanced procedure in the matter of prior consultations: First of all it must be taken into account that the population minorities at the national level are supported by the United Nations, since, the previous consultations are intended to protect at all costs the culture and environment of them, so, they can recognize and protect the moral values that are established in them and so, it can have a future benefit at the level of infrastructure and logistical performance without leaving aside the smallest communities that conforms the national territory.

A prior consultation is determined as a process that seeks a common good among the ethnic communities of the country and organizations interested in implementing improvements in all the productive systems of the country, through continuous feedback where the expectations and requirements of each of the parties are made known.

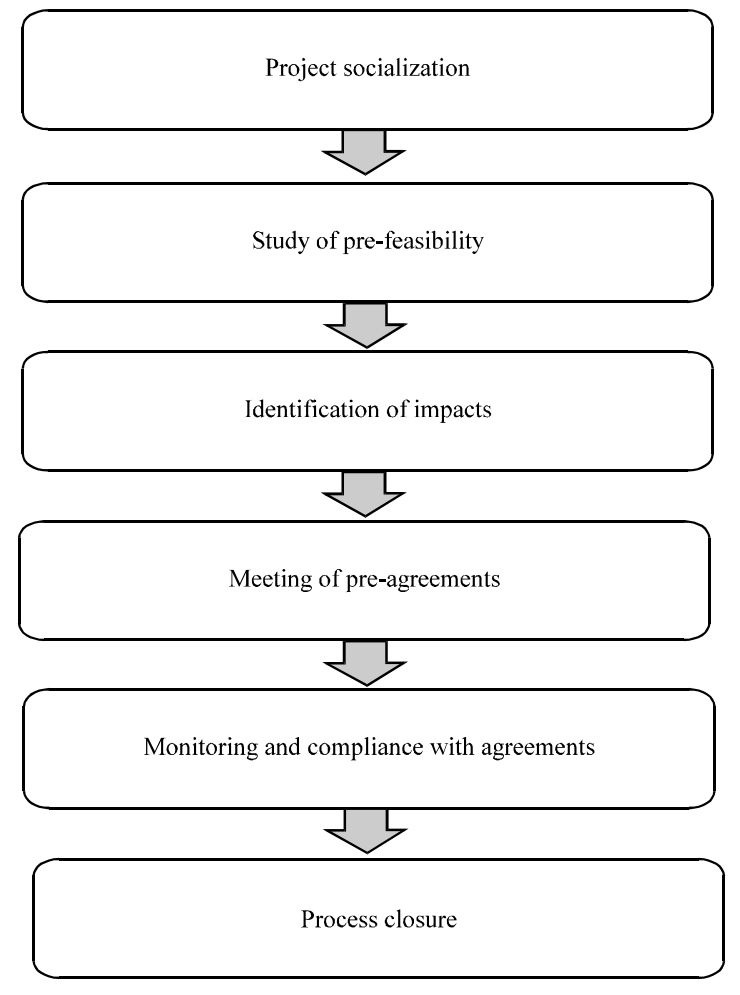

Fig. 3: Recommendations of a prior consultation

The organizations that supervise this type of processes at national level develop a series of recommendations that must be taken into account by the companies interested in making a prior consultation, Figure 3 illustrates this process in a general way (Padmavathi and Thangadurai, 2016; Amaya et al., 2017; Ariza et al., 2017). 
To review the technical-mechanical norms for freight vehicles and the supervision of their compliance, to give greater transparency and homogeneity to the procedures: Currently there is no antecedent of implementations of controls to the automotive fleet and for that reason the continuous improvement and the qualification in the logistic performance index for Colombia is negative.

In order to increase the reliability of the service that is being provided a new unified preventive control must be created and applied at the technical-mechanical level in all the companies involved within the system. So that, in this way a new regulation can be structured at the national level and with the help of the respective evaluating organizations a philosophy of continuous improvement is generated which not only helps to improve the score in the international indicator but also structures the companies that must be willing to change the model of providing their service if the market requires it (Padmavathi and Thangadurai, 2016; Amaya et al., 2017; Mukhopadhyay and Chaudhuri, 2015).

Specialized training program for driver training: One of the most important factors in the supply chain is how the service is provided; Since, this factor helps to increase positively the perception of customers. But how to achieve this if currently the level of service provision is very low in the national logistics system. It is here where the role of managers of large business organizations at the logistics level comes to life. Since, it is necessary to implement in a unified way a process of training the personnel in an ascending way in the management of the service in order to increase the reception of customers.

This research is the responsibility of both companies and higher education entities at the national level. So that, in this way it can be have a continuous training system with certification. But the task does not end here, organizations must establish the requirements that their employees must have in order to perform the corresponding tasks. Below are some aspects that will help this implementation to have more power within the department where it is applied (Padmavathi and Thangadurai, 2016; Amaya et al., 2017; Bradski and Kaehler, 2008):

- Define a training schedule

- Implement a career plan within companies

- Offer more diversity of training

- Have a fixed infrastructure for the provision of the service

- Increase requirements in the profiles of workers, so, they have the need to be in continuous training

- Certify all your programs
Acquire unified load tracking technology and perform a real-time pilot tracking test: Land transport is affected in certain cases by different factors that do not help it to be efficient, one of them may be the effects on the roads of the national territory. This is why it is recommended that a real-time control system be implemented with the supervision of private security companies. So, that when these events are presented, interested organizations can take corrective actions regarding the traceability that is measured from the moment of loading until the moment of delivery of the merchandise.

This integration of technological tools allows the establishment of a series of aids that will serve as an input for operational decision making, thus, achieving optimal performance criteria associated with the development of transport activities (Padmavathi and Thangadurai, 2016; Amaya et al., 2017; Brosnan and Sun, 2004).

Implementation of management practices in companies and commitments for formal hiring: The valuation that companies should have with their workers is a pillar for their growth. Having a good work environment projected to make the provision of services better every day. This is why organizations must improve working conditions with contractors, the implementation of career plans that exploit the interest of the members of the work group to overcome each day more, attests to how important the guild is for the company and its future results. On the other hand, the extra public and economic recognition that can be generated motivates even more that a common wealth is sought and that the goals that are met are fulfilled in the time required.

The human part is important and therefore, the research facilities must be optimal for the realization of it. The frequent change of vehicle fleets for newer models and the physical part of the company creates adequate environments for the whole working group, the improvement of good practices in the procedures also generates a continuous improvement that helps to make the business philosophy stronger and finally, the direct link between employees and companies and the elimination of intermediate employment companies strengthens the relationship between the worker's association and the business organization (Padmavathi and Thangadurai, 2016; Amaya et al., 2017; Brosnan and Sun, 2004). To end, the Table 2 identifies the different business organizations whether public or private that can make a difference when executing each of the short-term recommendations identified in the respective analysis (Padmavathi and Thangadurai, 2016; Lopez-Garcia et al., 2010). 
Table 2: Execution organizations

\begin{tabular}{|c|c|c|}
\hline \# Recommendation & $\begin{array}{l}\text { Organization } \\
\text { in charge }\end{array}$ & $\begin{array}{l}\text { Type of } \\
\text { recommendation }\end{array}$ \\
\hline 1 & $\begin{array}{l}\text { Ministry of Finance, } \\
\text { Ministry of Commerce, } \\
\text { Industry and Tourism, } \\
\text { public and private } \\
\text { companies }\end{array}$ & $\begin{array}{l}\text { Public-private } \\
\text { corporation }\end{array}$ \\
\hline 2 & $\begin{array}{l}\text { Public-private companies } \\
\text { interested, Ministry of } \\
\text { Environment and Sustainable } \\
\text { Development National } \\
\text { Govemment and National Ethnic } \\
\text { Communities }\end{array}$ & Regulatory action \\
\hline 3 & $\begin{array}{l}\text { Ministry of Transport and } \\
\text { Evaluation Entities }\end{array}$ & $\begin{array}{l}\text { Regulatory action, } \\
\text { Private supervision } \\
\text { companies }\end{array}$ \\
\hline 4 & $\begin{array}{l}\text { Transport companies, } \\
\text { Ministry of National } \\
\text { Education, Higher } \\
\text { Education Entities }\end{array}$ & $\begin{array}{l}\text { Public-private } \\
\text { corporation }\end{array}$ \\
\hline 5 & $\begin{array}{l}\text { Logistics Companies, } \\
\text { ICT Ministry, Private } \\
\text { Satellite Security Service }\end{array}$ & $\begin{array}{l}\text { Public-private } \\
\text { corporation }\end{array}$ \\
\hline 6 & $\begin{array}{l}\text { Ministry of Labor and } \\
\text { Productive Sector }\end{array}$ & Private action \\
\hline
\end{tabular}

\section{CONCLUSION}

Currently the Colombian government creates a series of research plans in the short, medium and long term in which there is a different commitment that has as its only purpose to obtain an internal improvement at the level of logistic performance within the evaluation index developed worldwide. But the improvement is not achieved only with the creation of work plans, the search for different ways of executing these work plans are those that really help to obtain the desired result. Since, in this way there are more guarantees for the fulfillment of the set and it is designated who is responsible for both the execution and the completion of each of the recommendations. The study analyzed who can be responsible for compliance with these premises and how they can proceed in order not only to improve the position within the international index but also how the internal national process can be improved at a logistical level.

\section{ACKNOWLEDGEMENTS}

This resrach was supported by the Universidad Distrital Francisco Jose de Caldas Technological Faculty. The views expressed in this study are not necessarily endorsed by the University. The researchers thank the research group ARMOS for the evaluation carried out on prototypes of ideas and strategies.

\section{REFERENCES}

Amaya, D., A. Rojas and D. Gutierrez, 2017. Algorithm for detection of Aonidiella Aurantii in citrus $\times$ tangelo fruits using DIP technique. Indian J. Sci. Technol., 10: $1-6$.

Ariza, H.M., F.H. Martinez and E. Jacinto, 2017. Visual patterns recognition in robotic platforms through the use of neural networks and image processing. Intl. J. Appl. Eng. Res., 12: $7770-7774$.

Bonin-Font, F., A. Ortiz and G. Oliver, 2008. Visual navigation for mobile robots: A survey. J. Intell. Rob. Syst., 53: 263-296.

Bradski, G. and A. Kaehler, 2008. Learning OpenCV: Computer Vision with the OpenCV Library. O'Reilly Media Inc., Sebastopol, CA., USA., ISBN-13: 9780596516130, Pages: 575.

Brosnan, T. and D.W. Sun, 2004. Improving quality inspection of food products by computer vision-a review. J. Food Eng., 61: 3-16.

Kumar, T. and K. Verma, 2010. A theory based on conversion of RGB image to Gray image. Intl. J. Comput. Appl., 7: 7-10.

Lopez-Garcia, F., G. Andreu-Garcia, J. Blasco, N. Aleixos and J.M. Valiente, 2010. Automatic detection of skin defects in citrus fruits using a multivariate image analysis approach. Comput. Electron. Agric., 71: 189-197.

Mukhopadhyay, P. and B.B. Chaudhuri, 2015. A survey of Hough transform. Pattern Recognit., 48: 993-1010.

Nandini, V., R.D. Vishal, C.A. Prakash and S. Aishwarya, 2016. A review on applications of machine vision systems in industries. Indian J. Sci. Technol., 9: 1-5.

Padmavathi, K. and K. Thangadurai, 2016. Implementation of RGB and grayscale images in plant leaves disease detection-comparative study. Indian J. Sci. Technol., 9: 1-6.

Wu, D. and D.W. Sun, 2013. Colour measurements by computer vision for food quality control-A review. Trends Food Sci. Technol., 29: 5-20. 